\title{
Acute Onset Neurological Disorders during Pregnancy: A Literature Review
}

\section{Doenças neurológicas de início durante a gravidez: análise crítica da literatura}

\author{
Zita Ferraz $^{1}$ Joana Parra ${ }^{2}$ Ana Luísa Areia ${ }^{1,3}$ Elsa Vasco ${ }^{1}$ Paulo Moura ${ }^{1,3}$ \\ ${ }^{1}$ Obstetrics Unit, Centro Hospitalar e Universitário de Coimbra, \\ Address for correspondence Zita da Costa Ferraz, MD, PhD, \\ Coimbra, Portugal \\ ${ }^{2}$ Neurology Department, Centro Hospitalar e Universitário de \\ Coimbra, Coimbra, Portugal \\ Obstetrics Unit, Centro Hospitalar e Universitário de Coimbra - Rua \\ Miguel Torga, 3030-165 Coimbra, Portugal \\ (e-mail: ferrazzita@gmail.com).
}

${ }^{3}$ Faculdade de Medicina, Universidade de Coimbra, Coimbra, Portugal

Rev Bras Ginecol Obstet 2017;39:560-568.

\section{Abstract \\ Keywords \\ - pregnancy \\ - Bell's palsy \\ - carpal tunnel syndrome \\ - headache \\ - cerebrovascular complications \\ - management}

\section{Resumo}

Objectives To characterize the most common peripheral and central neurological disorders during pregnancy.

Methods Original research and review of the literature on neurological complications during pregnancy. We searched for keywords related to the topic on different databases.

Results Pregnancy involves physiological changes that can trigger peripheral neurological and/or central nervous system pathologies, which can sometimes be associated with hypertensive disorders. A definitive diagnosis of neurological disorders can be made according to the trimester of pregnancy and the clinical findings. Carpal tunnel syndrome and peripheral facial palsy are common peripheral neurological disorders, more frequent in the second half of pregnancy. Central nervous disorders are more complex and a precise diagnosis must be made in order to improve perinatal outcomes, provide correct management and treatment and to prevent acute and long-term complications.

Conclusions It is possible to achieve a precise diagnosis, management and treatment of neurological disorders during pregnancy, but these require a multidisciplinary approach, crucial to improve perinatal outcomes.

Objetivos Caracterizar as alterações neurológicas centrais e periféricas mais comuns durante a gravidez.

Métodos Foi efetuada uma revisão da literatura acerca de complicações neurológicas durante a gravidez. Foram utilizadas diversas bases de dados usando palavras-chave relacionadas com o tema.

Resultados A gravidez envolve alterações fisiológicas que podem desencadear alterações neurológicas periféricas e/ou do sistema nervoso central, por vezes associadas a distúrbios hipertensivos. Um diagnóstico definitivo pode ser feito tendo received January 11, 2017 accepted April 18, 2017 published online June 26, 2017
DOI https://doi.org/ 10.1055/s-0037-1604058. ISSN 0100-7203.
Copyright $\odot 2017$ by Thieme Revinter

Publicações Ltda, Rio de Janeiro, Brazil
License terms

(c) (i) $\ominus$ (\$) 
Palavras-chave

- gravidez

- paralisia de Bell

- síndrome do túnel cárpico

- cefaleia

- complicações cerebrovasculares

- vigilância em conta o trimestre de gravidez e os achados clínicos encontrados. A síndrome do túnel carpal e a paralisia facial periférica são alterações neurológicas periféricas comuns que ocorrem mais frequentemente na segunda metade da gravidez. As alterações em termos do sistema nervoso central são mais complexas. Um diagnóstico preciso é fulcral, não só para melhorar os desfechos perinatais, mas também para efetuar uma vigilância e tratamento adequados e para prevenir complicações agudas e a longo prazo.

Conclusões Um diagnóstico preciso e um acompanhamento e tratamento apropriados dos distúrbios neurológicos durante a gravidez são ações exequíveis. Contudo, requerem uma abordagem multidisciplinar, crucial para melhorar os desfechos perinatais.

\section{Introduction}

Pregnancy is associated with anatomical and physiological changes, such as decreased vascular resistance, increased vascular permeability and cardiac output. These are essential to accommodate plasma volume expansion and guarantee perfusion of vital organs. Nevertheless, fluctuations in estrogen concentration can increase coagulation factors and lead, consequently, to an increased risk of thromboembolism. In these situations, elevated levels of progesterone induce vasodilation, vascular stasis and edema, which further increase the risk of thromboembolism. ${ }^{1}$

The risk of hypertension caused by the higher resistance in maternal systemic blood vessels, which occurs in cases of preeclampsia, can adversely affect blood flow in many organs (including liver, kidneys, brain and placenta). ${ }^{2,3}$ Thus, women with preeclampsia and eclampsia have an increased risk of complications, such as pulmonary edema, placental abruption, aspiration pneumonia, renal failure, hepatic failure and stroke. ${ }^{3,4}$

Some peripheral neuropathies (carpal tunnel syndrome, peripheral facial palsy) and some central neurological disorders (seizure, migraine, cerebrovascular malformations, epilepsy) may be more frequent during pregnancy due to an exacerbation of a preexisting neurological condition, or by an acute onset of a neurological disorder associated with physiological changes engendered by pregnancy (such as headache or vascular disorders). ${ }^{1,5-8}$

Both peripheral and central neurological disorders can occur during the three trimesters of pregnancy. So, an early and accurate diagnosis is essential to improve pregnancy management, treatment and subsequent perinatal outcomes.

The aim of this review is to describe and characterize the most common peripheral and central neurological disorders during pregnancy and subsequent management and treatment thereof.

\section{Methods}

A systematic search was conducted using Medline, PubMed, MeSH and ScienceDirect. Combinations of the search terms "pregnancy," "carpal tunnel syndrome," "Bell's palsy," "headache," "cerebral thrombosis," "cerebral hemorrhage," "diag- nosis," "management" and "treatment" were used. A total of 76 articles were included in this review, published between 2005 and 2017.

\section{Results}

Both peripheral and central neurological disorders can occur during the three trimesters of pregnancy and arise from specific changes occurring in each trimester ( - Table $\mathbf{1})$.

\section{Peripheral Neurological Disorders}

Carpal tunnel syndrome and peripheral facial palsy are common examples of minor peripheral neurological disorders in pregnancy. ${ }^{7-9}$ However, factors that predispose to neuropathies should be considered in pregnant women, including diabetes, thyroid disorders, and/or inherent neuropathies (Charcot-Marie-Tooth disease).

Although most neuropathies are usually reversible, associated disabilities or morbidities can limit function and require therapy. ${ }^{9}$

Carpal tunnel syndrome is a group of symptoms caused by compression of the median nerve in the carpal tunnel, characterized by numbness, tingling and weakness in the thumb, index, middle, half of the ring finger and parts of the palm of the hand (supplied by the median nerve). The incidence varies from 2 to $70 \%$ during pregnancy depending on the diagnostic method and the physician. . $^{70-12}$

Complaints occur most commonly in the second and third trimester ( - Table $\mathbf{1}$ ), in the morning and at night. They are associated with venous congestion and/or nerve compression upon wrist flexion during sleep. Hormonal changes, fluid accumulation with a predisposition to edema, nerve hypersensitivity and glucose level fluctuations can all increase the risk of pregnant women developing symptoms of carpal tunnel syndrome. ${ }^{7}$ Diagnosis is clinical and could be confirmed by electrodiagnostic testing. ${ }^{7,10}$

Conservative treatment is almost always appropriate and a complete recovery after pregnancy is the rule. In cases requiring intervention, first-line treatment includes overnight immobilization of the wrist with a splint in a neutral position or in slight extension. If necessary, local procedures such as an intracarpal steroid injection and surgery (with local anesthesia) are safe for mother and fetus. ${ }^{7}, 10-12$ 
Table 1 Summary of the characteristics of new-onset acute peripheral and central neurological disorders in pregnancy

\begin{tabular}{|c|c|c|c|c|}
\hline Peripheral Disorders & First trimester & Second trimester & Third trimester & Comments \\
\hline Carpal Tunnel Syndrome & + & ++ & +++ & $\begin{array}{l}\text { Pregnant women: } \\
\text { - shorter duration of symptoms } \\
\text { - } \uparrow \text { incidence in both hands } \\
\text { - weaker intensity of symptoms }\end{array}$ \\
\hline Bell's palsy & + & + & +++ & Rarely recurrent \\
\hline \multicolumn{5}{|l|}{ Central Disorders } \\
\hline \multicolumn{4}{|l|}{ Headache } & \multirow{4}{*}{$\begin{array}{l}\text { - MH is as a possible predictor of } \\
\text { complications in pregnancy (mis- } \\
\text { carriage, preeclampsia, eclampsia, } \\
\text { CVT, stroke, low birth weight) } \\
\downarrow \\
\text { - Inconsistent by deficient con- } \\
\text { trolled studies }\end{array}$} \\
\hline \multicolumn{4}{|l|}{$\mathrm{MH}$} & \\
\hline a) without aura & +++ & ++ & $+1-$ & \\
\hline b) with aura & + & ++ & +++ & \\
\hline \multicolumn{4}{|c|}{ Cerebrovascular complications } & \multirow{5}{*}{$\begin{array}{l}\text { - AVM typically occurs earlier (15-20 } \\
\text { weeks of GA) and in younger wo- } \\
\text { men ( } 20-25 \text { years-old) } \\
\text { - Aneurysm rupture occurs later } \\
\text { ( } 30-40 \text { weeks of GA) and in older } \\
\text { women ( } 30-35 \text { years-old) } \\
\text {-SAH occurs commonly as a result of } \\
\text { ruptured aneurysm }\end{array}$} \\
\hline - CVT & + & + & +++ & \\
\hline- AVM & +++ & + & + & \\
\hline - Aneurysm rupture & + & ++ & +++ & \\
\hline$-\mathrm{SAH}$ & (see comments) & (see comments) & (see comments) & \\
\hline
\end{tabular}

Abbreviations: AVM, arterial-venous malformation; CVT, cerebral vein thrombosis; GA, gestational age; MH, migraine headache; SAH, subarachnoid hemorrhage.

$+\rightarrow$ can occur; $++\rightarrow$ common; $+++\rightarrow$ very common; $-\rightarrow$ cessation; $\pm \rightarrow$ unchanged; $? \rightarrow$ unknown; $\emptyset \rightarrow$ inexistent.

Peripheral facial palsy, also called Bell's palsy, is an idiopathic facial neuropathy named after Sir Charles Bell, who first described this condition and its link to pregnancy. The incidence is around 28-45:100.000 pregnancies; it is rarely recurrent and it is more common in the third trimester (-Table 1). ${ }^{8,9}$

The most frequent symptoms are unilateral weakness of the muscles controlling facial expressions (smiling, closing eyelids), dry eyes and mouth, hyperacusis to acute sounds and loss of taste over the anterior two thirds of the tongue ipsilateral to the facial weakness. It may be preceded or accompanied by ipsilateral retroauricular pain; some studies reveal that the increased incidence in pregnancy may be related to hypertensive disorders of pregnancy (preeclampsia, gestational hypertension). ${ }^{9,13,14}$

There are no specific treatments studied for peripheral facial palsy. The affected eye must be kept patched and moist to prevent corneal abrasions. Some neurologists prescribe a short course of steroids to minimize clinical features and increase the probability of facial nerve recovery. ${ }^{9,15}$

\section{Central Neurological Disorders}

Headache is a common presenting complaint during pregnancy. ${ }^{16,17}$ Despite the strong link between hormonal changes and headache, the recognition of non-hormonal factors is crucial. A pulsating and unilateral headache, associated with nausea and/or vomiting and/or photophobia or phonophobia are typical symptoms of a migraine headache $(\mathrm{MH}))^{1,5,18,19}$

About $8 \%$ of women suffering from $\mathrm{MH}$ experience an increase in the attack frequency and pain intensity of migraine during pregnancy, affecting more often those women with $\mathrm{MH}$ with aura. ${ }^{20}$ New-onset migraine arising during pregnancy usually takes place during the first trimester. ${ }^{1,5,20}$ If de novo $\mathrm{MH}$ occurs, it is more likely to occur with aura. In general, $50-75 \%$ of women with preexisting $\mathrm{MH}$ without aura see an improvement or complete remission during pregnancy. This fact suggests that high stable placental estrogen levels, mainly during the second and third trimesters of pregnancy, could be beneficial to this pathology. 5,20,21

Studies have shown no difference in the incidence or course of $\mathrm{MH}$ between primiparous and multiparous women. $1,21,22$

The increase in estrogen levels can be the source of $\mathrm{MH}$ with aura in susceptible women. In general, women with $\mathrm{MH}$ (with or without aura) can be assured that there are no adverse effects on pregnancy's outcome or maternal health. Nevertheless, some retrospective studies suggest that $\mathrm{MH}$ has been mentioned as a possible predictor of complications in pregnancy, including miscarriage, preeclampsia, eclampsia, congenital abnormalities, cerebral venous sinus thrombosis, stroke, and low birth weight; these links remain inconsistent due to poorly controlled studies. ${ }^{1,16,23}$

\section{Imaging Studies}

Neuroradiology is important to exclude secondary causes of headache. Imaging findings are usually normal in migraine. The indications for imaging testing are the same as those for non-pregnant women. The exclusion of threatening secondary causes is essential, especially if "red flags" are present (-Fig. 1).

Magnetic resonance imaging (MRI) is safe during pregnancy; However, the use of gadolinium in pregnant women is 

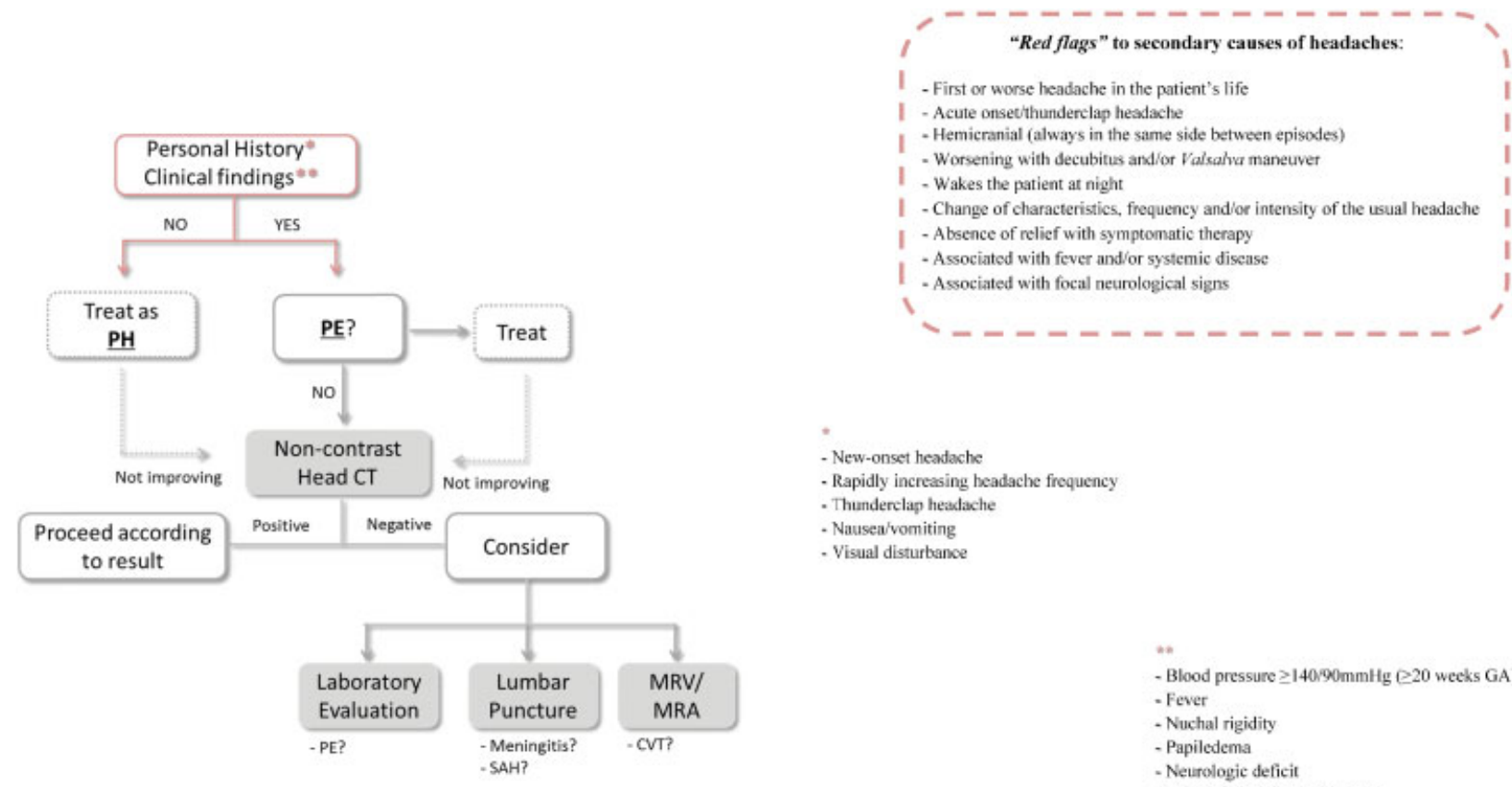

- New-onset headache

- Rapidly increasing beadache frequency

- Thunderclap headache

Nausea'vomiting

- Visual disturbance

Fig. 1 Approach to evaluation of headache in pregnant patient. Abbreviations: CT, computed tomography; MRA, magnetic resonance angiogram; MRV, magnetic resonance venogram; $\mathrm{PE}$, preeclampsia; $\mathrm{PH}$, primary headache; $\mathrm{SAH}$, subarachnoid hemorrhage.

controversial because it can cross the placenta (although it has not been shown to cause birth defects). ${ }^{16,21}$ Magnetic resonance imaging is recommended to assess the posterior fossa, while magnetic resonance arteriography (MRA) and magnetic resonance venography (MRV) are indicated to exclude vascular causes of headache. ${ }^{21}$ Computed tomography (CT) scan without contrast is an imaging option in pregnancy in selected cases; however, the risk of in utero exposure to ionizing radiation limits its use. ${ }^{16,21}$

When imaging studies are indicated, MRI should be used due to its higher resolution, increased sensitivity, and lack of ionizing radiation. The use of CT scan should be considered in selected cases, due to its wider availability and lower cost. Contrast agents should be avoided, unless absolutely necessary. ${ }^{16,24}$

\section{Symptomatic Treatment}

Medical therapy should be selected taking into consideration adverse effects on the fetus. Symptomatic treatment during pregnancy is challenging and a detailed discussion of the risks and benefits of each medical treatment is essential (-Table 2 ). First-line therapy includes an analgesic and an antiemetic drug. ${ }^{1,25,26}$ The pain management options for use during pregnancy described below are in accordance with the US Food and Drug Administration (FDA) recommendations.

\section{Analgesics}

Acetaminophen (category B for intravenous administration) is the analgesic of choice for short-term relief of mild to moderate pain during pregnancy, ${ }^{25,27}$ and it is considered a safe drug at therapeutic doses of $\leq 4$ g per day for an adult. ${ }^{28}$ An analgesic dose of acetylsalicylic acid (100mg/day) is safe in the first and second trimesters, but it should be used with caution near term (category D) due to its effect on platelet function, causing an increased risk of prolonged labor, postpartum hemorrhage, neonatal bleeding and premature closure of the fetal ductus arteriosus. ${ }^{25}$ Metamizol/dipyrone (category C), by oral or intravenous route, has been demonstrated to be effective in the treatment of migraine attacks, but the risk of agranulocytosis, renal failure and hypotension limits its use. ${ }^{29,30}$ Also, it has been associated with Wilms tumor, with risk of infant leukemia and there are several case reports suggesting its association with oligohydramnios and closure of the ductus arteriosus when used in the third trimester. ${ }^{30-33}$ It was taken off the US market, but it is still available in some European and Latin American countries. ${ }^{27}$

\section{Non-Steroidal Antiinflammatory Drugs (NSAIDS)}

Studies do not satisfactorily support their use during pregnancy, except for ibuprofen (category C prior to 30 weeks and category $\mathrm{D} \geq 30$ weeks). Moreover, persistent exposure to NSAIDs, or any level of exposure to them after 30 weeks, is associated with an increased risk of premature closure of the fetal ductus arteriosus and oligohydramnios due to its inhibitory effect on prostaglandin activity. ${ }^{25,34,35}$

\section{Triptans}

In contrast to analgesics, the efficacy of triptans is due to the specifically targeted pathogenesis of $\mathrm{MH} .{ }^{36}$ The safety of triptans during pregnancy is still questionable and their sustained use is discouraged unless no other treatment is successful. Sumatriptan and rizatriptan (category B) have not been associated with congenital abnormalities or adverse outcomes $^{25,29}$ and, to date, the risk of major malformations has been reported to be equal to the baseline risk in the general population (1\% to $3 \%)^{36}$ 
Table 2 Symptomatic drugs used during pregnancy

\begin{tabular}{|c|c|c|c|}
\hline Drug & First Trimester & Second Trimester & Third Trimester \\
\hline $\begin{array}{l}\text { Acetaminophen/Paracetamol }(\leq 4 \mathrm{~g}) \\
\text { Metamizol (Dipyrone) }\end{array}$ & $\begin{array}{l}(;) \\
\text { ID }\end{array}$ & $\begin{array}{l}\stackrel{-}{;} \\
\text { ID }\end{array}$ & $\begin{array}{l}+; \\
\text { Avoid }\end{array}$ \\
\hline $\begin{array}{l}\text { Aspirin ( } \leq 100 \mathrm{mg} / \text { day }) \\
\text { Ibuprofen } \\
\text { Diclofenac } \\
\text { Naproxen }\end{array}$ & (:) & (:) & Avoid \\
\hline $\begin{array}{l}\text { Metoclopramide } \\
\text { Promethazine } \\
\text { Ondansetron } \\
\text { Prochlorperazine* } \\
\text { Chlorpromazine* } \\
\text { Prednisolone* }\end{array}$ & (;) & (:) & (:) \\
\hline Ergotamine & $\mathrm{Cl}$ & $\mathrm{Cl}$ & $\mathrm{Cl}$ \\
\hline $\begin{array}{l}\text { Almotriptan } \\
\text { Eletriptan } \\
\text { Frovatriptan } \\
\text { Zolmitriptan }\end{array}$ & ID & ID & ID \\
\hline $\begin{array}{l}\text { Naratriptan } \\
\text { Rizatriptan } \\
\text { Sumatriptan }\end{array}$ & $?$ & $?$ & $?$ \\
\hline
\end{tabular}

Abbreviations: $\mathrm{Cl}$, contraindicated; ID, insufficient data; ?, limited data, but probably safe.

(;), no evidence of harm; (;) data suggest unlikely to cause harm.

*, for emergency treatment of migraine not responding to standard measure

${ }^{* *}$, contraindicated in the US market. Available in some European and Latin-American countries.

\section{Antiemetics}

Metoclopramide (category B) is commonly used in pregnancy for its antiemetic and gastric prokinetic effects. ${ }^{25,26}$ Extrapyramidal reactions are the most common acute side effect of metoclopramide with a reported incidence of $0.2 \%{ }^{37,38}$ Promethazine (category $\mathrm{C}$ in the first trimester and $\mathrm{B}$ thereafter) and prochlorperazine (category C) are dopamine receptor antagonists and can be used combined with NSAIDs or opioids; ${ }^{39}$ the latter may be associated with congenital heart defects and cleft palate. ${ }^{19}$ Ondansetron (category B) should not be used as first-line treatment. Beginning the treatment after 10 weeks of gestational age (GA) minimizes the risks of teratogenicity. ${ }^{40}$

Cerebrovascular disorders are uncommon in reproductive-aged women. Pregnancy-induced physiological changes increase the risk of cerebral venous thrombosis, as also do the existence of preeclampsia/eclampsia and thrombophilia. ${ }^{39,41-43}$

\section{Cerebral venous thrombosis}

Most pregnancy-related cerebral venous thrombosis (CVT) occur in the third trimester of pregnancy and puerperium (-Table 1), accounting for 27 to $57 \%$ of all pregnancy-related strokes. ${ }^{44,45}$ Common presenting complaints include headache (typically sub-acute), focal neurological deficits, seizures, altered mental status and signs of high intracranial pressure such as papilloedema. ${ }^{22,46}$ History of a previous extracerebral venous thrombotic event is also associated with adverse pregnancy outcomes and has a 3-4-fold higher risk of venous thrombotic event during subsequent pregnan- cies. ${ }^{44}$ Headache with focal neurological signs or seizures should raise the suspicion of CVT. ${ }^{2,21}$ Diagnosis is based on neuroimaging, with MRI being preferable to CT scan because of its higher resolution, sensitivity, and lack of ionizing radiation. ${ }^{16,21,24}$ In most cases, CT results will show nonspecific edema or infarction. Fetal outcomes after a CVT seem to be favorable and have low mortality rates. ${ }^{43,44,47,48}$ Pregnancy and the puerperium are periods of high-risk for thrombotic complications, particularly the third trimester of pregnancy and the first four weeks postpartum. ${ }^{49-52}$

Anticoagulation during pregnancy must be individualized according to the co-existence of risk factors. ${ }^{13,43,47}$ Evidence suggests the use of maintenance anticoagulation for a period of 3 months in presence of high risk factors, and for at least 6-12 months in patients with idiopathic cases (potential etiologies include paroxysmal atrial fibrillation, patent foramen ovale, atherosclerotic plaques of the aortic arch, congenital and acquired prothrombotic states) and women with mild hereditary thrombophilia (heterozygous factor $\mathrm{V}$ Leiden or prothrombin G20210A mutation). Indefinite anticoagulation should be reserved to patients with idiopathic cases, recurrent episodes, and to those with high-risk thrombophilia (antithrombin, protein $C$ or protein $S$ deficiency, homozygous factor V Leiden or prothrombin G20210A mutation, antiphospholipid antibodies and combined abnormalities). ${ }^{52-55}$

\section{Hemorrhagic disorders}

Bleeding of an arteriovenous malformation (AVM) is a cerebrovascular complication that is noticeable in younger women (20-25 years-old) and earlier in pregnancy (15-20 weeks 
of GA); in contrast, aneurysm rupture occurs more commonly in older women (30-35 years-old) and between 30-40 weeks of GA. ${ }^{6,56}$ Possible mechanisms include hormonal changes (that lead to a predisposition to the development, enlargement and rupture of an aneurysm), increase in cardiac output by $60 \%$ in the second trimester and higher blood volume in the third trimester, which all increase the risk of aneurysm rupture. Women generally present with an abrupt onset of a severe and unusual headache (thunderclap headache), nausea and vomiting, photophobia, syncope and focal neurological deficits. If brain CT without contrast does not provide a diagnosis, a lumbar puncture should be performed. ${ }^{57}$ For hemorrhagic AVM, cerebral angiography is necessary. An unruptured AVM in pregnancy, with no bleeding risk factors (aneurysm, venous ectasia), should be followed conservatively. ${ }^{6,56,58}$ In contrast, an emergency surgery is necessary for a bleeding cerebral AVM, particularly if the existence of a hematoma causes worsening of neurological symptoms or cerebral herniation. ${ }^{14,56,58}$

Endovascular embolization for cerebral AVM in pregnancy should be performed per clinical manifestations and angiographic features. Several studies reported that this procedure during pregnancy is safe and effective. ${ }^{56,59,60}$ The radiation dose of endovascular and stereotactic radiotherapy during pregnancy is also safe. ${ }^{16}$ However, non-radiation procedures are preferred during pregnancy. In cases of unruptured AVM, vaginal delivery or caesarean section should depend on obstetric criteria. ${ }^{56,61}$

Subarachnoid hemorrhage (SAH) occurs most commonly because of ruptured aneurysm or AVM. The frequency of SAH in pregnancy is 5.8:100.000 deliveries in the United States of America. ${ }^{62}$ The most common symptom is severe headache. Computed tomography scan is the diagnostic exam of choice as it can identify hyperdense signal provided by the extravasated blood in the basal cisterns. ${ }^{24,57}$ It is unclear whether the risk of SAH is increased during pregnancy and the puerperium and there are no formal studies to support optimal obstetric management of pregnant women with SAH. Mode of delivery is based solely on obstetric criteria. $^{58,61-63}$

\section{Discussion}

Pregnancy is associated with a risk of thromboembolism and can lead to neurological disorders. So, women who present with acute neurological symptoms require a meticulous diagnostic evaluation ${ }^{1-3,64}$ Carpal tunnel syndrome and peripheral facial palsy are common examples of peripheral neurological disorders, which occur more often in the third trimester due to physiologic changes during pregnancy. $7,10,11,65,66$ Generally, surgery is not required and medical treatment is satisfactory. ${ }^{10,11,65}$ However, some women can maintain symptoms in the first three years post-partum. ${ }^{10,12}$

Central nervous system disorders are more complex. The acknowledgment of symptoms and imaging testing, if necessary, are extremely important to attain the correct diagnosis. Magnetic resonance imaging is safe during pregnancy and CT scan should be avoided and used only if absolutely necessary. ${ }^{16,21}$ Both diagnosis and management of headache in pregnant women present several challenges. Migraine is the most common and well-studied type of headache and it is divided in two main subtypes: with aura, occurring predominantly in the third trimester; and without aura, most common in the first trimester, improving in the third trimester. $^{1,5,20}$ In contrast, $\sim 8 \%$ of women experience increased frequency or intensity of $\mathrm{MH}$ during pregnancy. ${ }^{5}$ Data showed no difference in the incidence or course of $\mathrm{MH}$ between primiparous and multiparous women. ${ }^{1,21,22}$ Symptomatic treatment during pregnancy is challenging and should be selected taking into consideration adverse effects on the fetus. The literature is consensual that analgesic (such as acetaminophen) and antiemetic drugs (such as metoclopramide) are the first-line therapy of choice. ${ }^{25,27}$ Recently, a preliminary study with recommended doses of acetaminophen was performed to investigate the potential effect of perinatal exposure on metabolic function in mice offspring. The authors concluded that acetaminophen may be associated with impaired glucose metabolism, increased plasma insulin level, and reduced liver glycogen content; however, further investigation is warranted to demonstrated this potential association. ${ }^{67}$ Generally, acetaminophen is considered a safe drug at therapeutic doses. However, acetaminophen overdose remains the most common cause of acute liver failure in the western world, ${ }^{68}$ and women must be warned that safe dosage needs to be respected. Some triptans (sumatriptan and rizatriptan) can be used, although their safety in pregnancy remains unknown..$^{25,29,36}$ Non-steroidal anti-inflammatory drugs should be avoided mainly in the third trimester due to its association with premature closure of the foetal ductus arteriosus, oligohydramnios and risk of postpartum hemorrhage. ${ }^{25,34,35}$ For all these facts, medical treatment has to be conscientious, maintaining doses as low as possible, individualized to each woman. The prognosis of migraine (with or without aura) is favorable and literature does not provide evidence of complications. ${ }^{5,20}$ Nevertheless, perinatal adverse outcomes can occur in women with no evidence of remission or amelioration of migraine attacks. $^{69,70}$ So, $\mathrm{MH}$ should be considered a potential risk factor in obstetric care and has to be managed by a multidisciplinary team.

Cerebral venous thrombosis frequently occurs during the third trimester and puerperium. ${ }^{44,49-51}$ The literature is not consensual about the risk of recurrence of CVT. Generally, fetal outcome of a pregnancy after a CVT seems to be favorable. ${ }^{43-45,47}$ The risk of stroke is elevated during the first year postpartum, lowering in subsequent years. ${ }^{71}$ However, history of a previous extracerebral venous thrombotic event is associated with adverse pregnancy outcome and has a 3-16-fold higher risk of venous thrombotic event during subsequent pregnancies. ${ }^{44,72}$ Cerebral venous thrombosis recurrence is 80 -fold higher than the baseline risk described in general population studies. ${ }^{72}$ Mehraein et al $^{73}$ studied the outcomes of 21 pregnancies with a previously treated CVT. Low-dose heparin was given subcutaneously during the course of 5 of these pregnancies, while no anticoagulation was given during the course of the remaining 14 pregnancies 
and puerperium periods. None of patients had recurrence of CVT during pregnancy and puerperium and no extracerebral vascular thromboembolism occurred. They concluded that a history of CVT does not justify a negative advice on pregnancy in women. Current guidelines of the Royal College of Obstetricians and Gynaecologists ${ }^{74}$ for the prevention of thromboembolism defend that all women should undergo a documented assessment of risk factors in early pregnancy or pre-pregnancy and risk assessment should be repeated intrapartum or immediately postpartum. Women with a previous episode of thromboembolism (associated with antithrombin deficiency or with recurrent episodes of thromboembolism) should be offered thromboprophylaxis with a higher dose of anticoagulant therapy antenatally and for 6 weeks postpartum (or until returned to oral anticoagulant therapy after delivery). Instead, women in whom the original episode of thromboembolism was unprovoked/idiopathic or related to estrogen (for instance, in pregnancy) should be offered thromboprophylaxis with anticoagulant therapy throughout the antenatal period. In terms of the peripartum period, a recent integrated analysis of two prospective studies concluded that antithrombin concentrate is safe and effective in reducing venous thromboembolism if administered over an average period of 4 days. ${ }^{75,76}$ As so, more studies are warranted to define the real risk of thromboembolism in subsequent pregnancies and anticoagulation therapy to prevent complications and risk of recurrence in future pregnancies; the risk of thromboembolism should be discussed with women at risk and the reasons for individual recommendations explained. ${ }^{13,43,47,51,54,55}$

Arteriovenous malformation complications are more frequent in the first trimester, contrasting to aneurysm rupture, which occurs more commonly in the second half of pregnancy; ${ }^{6,56}$ both can lead to SAH. It is consensual that imaging investigation is vital and, during pregnancy, MRI is preferable to CT scan because of its higher resolution, sensitivity, and lack of ionizing radiation. In addition, MRV and MRA can be performed for the exclusion of vascular disorders and contrast agents cause adverse fetal effects and should avoided, unless absolutely necessary for an accurate diagnosis. ${ }^{16,21}$

Data are consistent that the appropriate delivery in cases of neurological complications remains undefined and the decision of the way should be based on obstetric criteria if the hemorrhagic risk has been removed. $6,58,61,63$

After appropriate diagnosis, proper treatment and followup are extremely important. In cases of cerebrovascular complications, the management and follow-up by a multidisciplinary team is mandatory. With scientific advances, the ability to diagnose and discriminate different causes of acute neurological symptoms is likely to progress. Because most of these conditions are rare, an early transfer to a Reference Centre and a multidisciplinary approach is essential to improve maternal and fetal outcomes.

\section{Conclusions}

Pregnancy is characterized by anatomic and physiologic changes that can trigger or potentiate neurological com- plaints. According to the pregnancy trimester, clinical findings, maternal age and risk factors, a definitive diagnosis of central or peripheral neurological disorders can be made, with appropriate management. An adequate treatment and supervision of these conditions are extremely important, with a multidisciplinary approach being essential to improve outcomes and prevent acute and long-term complications.

\section{Funding}

This research received no specific grant from any funding agency in the public, commercial, or not-for-profit sectors.

\section{Conflict of Interest}

The authors declare they have no conflict of interest.

\section{References}

1 Sacco S, Ricci S, Degan D, Carolei A. Migraine in women: the role of hormones and their impact on vascular diseases. J Headache Pain 2012;13(03):177-189

2 Prabhu TRB. Cerebrovascular complications in pregnancy and puerperium. J Obstet Gynaecol India 2013;63(02):108-111

3 Wang Y, Hao M, Sampson S, Xia J. Elective delivery versus expectant management for pre-eclampsia: a meta-analysis of RCTs. Arch Gynecol Obstet 2017;295(03):607-622

4 Cipolla MJ, Sweet JG, Chan SL. Cerebral vascular adaptation to pregnancy and its role in the neurological complications of eclampsia. J Appl Physiol (1985) 2011;110(02):329-339

5 Karlı N, Baykan B, Ertaş M, et al; Turkish Headache Prevalence Study Group. Impact of sex hormonal changes on tension-type headache and migraine: a cross-sectional population-based survey in 2,600 women. J Headache Pain 2012;13(07):557-565

6 Kataoka H, Miyoshi T, Neki R, Yoshimatsu J, Ishibashi-Ueda H, Iihara K. Subarachnoid hemorrhage from intracranial aneurysms during pregnancy and the puerperium. Neurol Med Chir (Tokyo) 2013;53(08):549-554

7 Zyluk A. Carpal tunnel syndrome in pregnancy: a review. Pol Orthop Traumatol 2013;78:223-227

8 Monini S, Lazzarino AI, Iacolucci C, Buffoni A, Barbara M. Epidemiology of Bell's palsy in an Italian Health District: incidence and case-control study. Acta Otorhinolaryngol Ital 2010;30(04):198

9 Shiny Sherlie V, Varghese A. ENT changes of pregnancy and its management. Indian J Otolaryngol Head Neck Surg 2014; 66(Suppl 1):6-9

10 Khosrawi S, Maghrouri R. The prevalence and severity of carpal tunnel syndrome during pregnancy. Adv Biomed Res 2012;1:43

11 Meems M, Truijens S, Spek V, Visser LH, Pop VJ. Prevalence, course and determinants of carpal tunnel syndrome symptoms during pregnancy: a prospective study. BJOG 2015;122(08):1112-1118

12 Padua L, Di Pasquale A, Pazzaglia C, Liotta GA, Librante A, Mondelli M. Systematic review of pregnancy-related carpal tunnel syndrome. Muscle Nerve 2010;42(05):697-702

13 Pourrat O, Neau JP, Pierre F. Bell's palsy in pregnancy: underlying HELLP syndrome or pre-eclampsia? Obstet Med 2013;6(03): 132-133

14 Juan YC, Au HK, Hsu JJ, Ma PC, Liu WM, Jeng CJ. Bell palsy and preeclampsia superimposed on chronic hypertension. Taiwan J Obstet Gynecol 2010;49(02):223-224

15 Murthy JM, Saxena AB. Bell's palsy: Treatment guidelines. Ann Indian Acad Neurol 2011;14(Suppl 1):S70-S72 
16 Robbins MS, Farmakidis C, Dayal AK, Lipton RB. Acute headache diagnosis in pregnant women: a hospital-based study. Neurology 2015;85(12):1024-1030

17 Turner DP, Smitherman TA, Eisenach JC, Penzien DB, Houle TT. Predictors of headache before, during, and after pregnancy: a cohort study. Headache 2012;52(03):348-362

18 Facchinetti F, Allais G, Nappi RE, et al. Migraine is a risk factor for hypertensive disorders in pregnancy: a prospective cohort study. Cephalalgia 2009;29(03):286-292

19 Contag SA, Mertz HL, Bushnell CD. Migraine during pregnancy: is it more than a headache? Nat Rev Neurol 2009;5(08):449-456

20 Kvisvik EV, Stovner LJ, Helde G, Bovim G, Linde M. Headache and migraine during pregnancy and puerperium: the MIGRA-study. J Headache Pain 2011;12(04):443-451

21 Schoen JC, Campbell RL, Sadosty AT. Headache in pregnancy: an approach to emergency department evaluation and management. West J Emerg Med 2015;16(02):291-301

22 Sasidharan PK. Cerebral vein thrombosis misdiagnosed and mismanaged. Thrombosis 2012;2012:210676

23 Cripe SM, Frederick IO, Qiu C, Williams MA. Risk of preterm delivery and hypertensive disorders of pregnancy in relation to maternal co-morbid mood and migraine disorders during pregnancy. Paediatr Perinat Epidemiol 2011;25(02):116-123

24 Hacein-Bey L, Varelas PN, Ulmer JL, Mark LP, Raghavan K, Provenzale JM. Imaging of cerebrovascular disease in pregnancy and the puerperium. AJR Am J Roentgenol 2016;206(01):26-38

25 Sarchielli P, Granella F, Prudenzano MP, et al. Italian guidelines for primary headaches: 2012 revised version. J Headache Pain 2012; 13(Suppl 2):S31-S70

26 Calhoun AH, Peterlin BL. Treatment of cluster headache in pregnancy and lactation. Curr Pain Headache Rep 2010;14(02): 164-173

27 Rivera Díaz R, Lopera Rivera A. Management of non-obstetric pain during pregnancy. Review article. Colomb J Anesthesiol. 2012; 40(03):213-223

28 Jaeschke H. Acetaminophen: dose-dependent drug hepatotoxicity and acute liver failure in patients. Dig Dis 2015;33(04): 464-471

29 Torelli P, Jensen R. Headache diaries and calendars. Handb Clin Neurol 2010;97:137-146

30 Weintraub A, Mankuta D. Dipyrone-induced oligohydramnios and ductus arteriosus restriction. Isr Med Assoc J 2006;8(10): 722-723

31 Arruza Gómez L, Corredera Sánchez A, Montalvo Montes J, de Marco Guilarte E, Moro Serrano M. Intrauterine closure of the ductus arteriosus probably associated with the taking of metamizole during the third trimester. An Pediatr (Barc) 2008;68(06): 626-627

32 Bar-Oz B, Clementi M, Di Giantonio E, et al. Metamizol (dipyrone, optalgin) in pregnancy, is it safe? A prospective comparative study. Eur J Obstet Gynecol Reprod Biol 2005;119(02):176-179

33 Zanrosso CW, Emerenciano M, Gonçalves BA, Faro A, Koifman S, Pombo-de-Oliveira MS. N-acetyltransferase 2 polymorphisms and susceptibility to infant leukemia with maternal exposure to dipyrone during pregnancy. Cancer Epidemiol Biomarkers Prev 2010;19(12):3037-3043

34 Shastri AT, Abdulkarim D, Clarke P. Maternal diclofenac medication in pregnancy causing in utero closure of the fetal ductus arteriosus and hydrops. Pediatr Cardiol 2013;34(08):1925-1927

35 Ndour DD. Maternal use of non-steroidal antiinflammatory drugs and closure of the ductus arteriosus. Pan Afr Med J 2016;25:251

36 Duong S, Bozzo P, Nordeng H, Einarson A. Safety of triptans for migraine headaches during pregnancy and breastfeeding. Can Fam Physician 2010;56(06):537-539

37 Jo YY, Kim YB, Yang MR, Chang YJ. Extrapyramidal side effects after metoclopramide administration in a post-anesthesia care unit -A case report-. Korean J Anesthesiol 2012;63(03):274-276
38 Yis U, Ozdemir D, Duman M, Unal N. Metoclopramide induced dystonia in children: two case reports. Eur J Emerg Med 2005; 12(03):117-119

39 Bordini CA, Roesler C, Carvalho DdeS, et al. Recommendations for the treatment of migraine attacks - a Brazilian consensus. Arq Neuropsiquiatr 2016;74(03):262-271

40 Kennedy D. Ondansetron and pregnancy: Understanding the data. Obstet Med 2016;9(01):28-33

41 Arai N, Tabuse M, Nakamura A, Miyazaki H. Malignant isolated cortical vein thrombosis with type II protein $S$ deficiency: a case report. BMC Neurol 2016;16:69

42 Hosley CM, McCullough LD. Acute neurological issues in pregnancy and the peripartum. Neurohospitalist 2011;1(02):104-116

43 Aracic N, Roje D, Jakus IA, Bakotin M, Stefanovic V. The impact of inherited thrombophilia types and low molecular weight heparin treatment on pregnancy complications in women with previous adverse outcome. Yonsei Med J 2016;57(05):1230-1235

44 Meng R, Ji X, Wang X, Ding Y. The etiologies of new cases of cerebral venous sinus thrombosis reported in the past year. Intractable Rare Dis Res 2012;1(01):23-26

45 Cantu-Brito C, Arauz A, Aburto Y, Barinagarrementeria F, RuizSandoval JL, Baizabal-Carvallo JF. Cerebrovascular complications during pregnancy and postpartum: clinical and prognosis observations in 240 Hispanic women. Eur J Neurol 2011;18(06): 819-825

46 Edlow JA, Caplan LR, O'Brien K, Tibbles CD. Diagnosis of acute neurological emergencies in pregnant and post-partum women. Lancet Neurol 2013;12(02):175-185

47 Coriu L, Ungureanu R, Talmaci R, et al. Hereditary Thrombophilia and thrombotic events in pregnancy: single-center experience. J Med Life 2014;7(04):567-571

48 Gupta R, Aggarwal M, Patil S, Vyas V. Cerebral venous thrombosis associated with pregnancy: a case report. IOSR J Dent Med Sci. 2015;14(05):43-45

49 Shah M, Agarwal N, Gala NB, Prestigiacomo CJ, Gandhi CD. Management of dural venous sinus thrombosis in pregnancy. EJVES Extra 2014;27(05):e41-e42

50 Nie Q, Guo P, Ge J, Qiu Y. Cerebral venous sinus thrombosis with cerebral hemorrhage during early pregnancy. Neurosciences (Riyadh) 2015;20(01):48-51

51 Saposnik G, Barinagarrementeria F, Brown RD Jr, et al; American Heart Association Stroke Council and the Council on Epidemiology and Prevention. Diagnosis and management of cerebral venous thrombosis: a statement for healthcare professionals from the American Heart Association/American Stroke Association. Stroke 2011;42(04):1158-1192

52 Bereczki D Jr, Szegedi N, Szakács Z, Gubucz I, May Z. Cryptogenic postpartum stroke. Neurol Neurochir Pol 2016;50(05):370-373

53 Einhäupl K, Stam J, Bousser MG, et al; European Federation of Neurological Societies. EFNS guideline on the treatment of cerebral venous and sinus thrombosis in adult patients. Eur J Neurol 2010;17(10):1229-1235

54 Marwah S, Shailesh GH, Gupta S, Sharma M, Mittal P. Cerebral venous thrombosis in pregnancy-a poignant allegory of an unusual case. J Clin Diagn Res 2016;10(12):QD08-QD09

55 Hafed BM, Houcem R, Wassim S, et al. Clinical and therapeutic aspects of post-partum cerebral thrombophlebites. Pan Afr Med J 2016;25:248

56 Liu XJ, Wang S, Zhao YL, et al. Risk of cerebral arteriovenous malformation rupture during pregnancy and puerperium. Neurology 2014;82(20):1798-1803

57 Grasso G, Alafaci C, Macdonald RL. Management of aneurysmal subarachnoid hemorrhage: State of the art and future perspectives. Surg Neurol Int 2017;8:11

58 Pereira CE, Lynch JC. Management strategies for neoplastic and vascular brain lesions presenting during pregnancy: A series of 29 patients. Surg Neurol Int 2017;8:27 
59 Nossek E, Ekstein M, Rimon E, Kupferminc MJ, Ram Z. Neurosurgery and pregnancy. Acta Neurochir (Wien) 2011;153(09):1727-1735

60 Ishii A, Miyamoto S. Endovascular treatment in pregnancy. Neurol Med Chir (Tokyo) 2013;53(08):541-548

61 Kalani MY, Zabramski JM. Risk for symptomatic hemorrhage of cerebral cavernous malformations during pregnancy. J Neurosurg 2013;118(01):50-55

62 Bateman BT, Olbrecht VA, Berman MF, Minehart RD, Schwamm LH, Leffert LR. Peripartum subarachnoid hemorrhage: nationwide data and institutional experience. Anesthesiology 2012;116(02): 324-333

63 Tiel Groenestege AT, Rinkel GJE, van der Bom JG, Algra A, Klijn CJM. The risk of aneurysmal subarachnoid hemorrhage during pregnancy, delivery, and the puerperium in the Utrecht population: case-crossover study and standardized incidence ratio estimation. Stroke 2009;40(04):1148-1151

64 Misra UK, Kalita J, Tripathi GM, Bhoi SK. Is $\beta$ endorphin related to migraine headache and its relief? Cephalalgia 2013;33(05):316-322

65 Osterman M, Ilyas AM, Matzon JL. Carpal tunnel syndrome in pregnancy. Orthop Clin North Am 2012;43(04):515-520

66 Finsen V, Zeitlmann H. Carpal tunnel syndrome during pregnancy. Scand J Plast Reconstr Surg Hand Surg 2006;40(01):41-45

67 Wu K, Guo C, Lu X, Wu X, Pan H, Su M. Impact of perinatal exposure to acetaminophen on hepatocellular metabolic function in offspring. Am J Transl Res 2016;8(12):5646-5652

68 Katarey D, Verma S. Drug-induced liver injury. Clin Med (Lond) 2016;16(Suppl 6):s104-s109

69 Blair EM, Nelson KB. Migraine and preterm birth. J Perinatol 2011; 31(06):434-439
70 Chen HM, Chen SF, Chen YH, Lin HC. Increased risk of adverse pregnancy outcomes for women with migraines: a nationwide population-based study. Cephalalgia 2010;30(04): 433-438

71 Cheng CA, Lee JT, Lin HC, et al. Pregnancy increases stroke risk up to 1 year postpartum and reduces long-term risk. QJM 2017; (Jan):9; [ Epub ahead of print ]

72 Aguiar de Sousa D, Canhão P, Ferro JM. Safety of pregnancy after cerebral venous thrombosis: a systematic review. Stroke 2016; 47(03):713-718

73 Mehraein S, Ortwein H, Busch M, Weih M, Einhäupl K, Masuhr F. Risk of recurrence of cerebral venous and sinus thrombosis during subsequent pregnancy and puerperium. J Neurol Neurosurg Psychiatry 2003;74(06):814-816

74 Royal College of Obstetricians and Gynaecologists [Internet] Thrombosis and embolism during pregnancy and the puerperium, reducing the risk (Green-top Guideline No. 37a). London: RCOG; 2015 [cited 2016 Jul 17]. Available from: <https://www.rcog.org uk/en/guidelines-research-services/guidelines/gtg37a/>

75 Paidas MJ, Triche EW, James AH, et al. Recombinant Human antithrombin in pregnant patients with hereditary antithrombin deficiency: integrated analysis of clinical data. Am J Perinatol 2016;33(04):343-349

76 Paidas MJ, Forsyth C, Quéré I, Rodger M, Frieling JT, Tait RC; Recombinant Human Antithrombin Study Group. Perioperative and peripartum prevention of venous thromboembolism in patients with hereditary antithrombin deficiency using recombinant antithrombin therapy. Blood Coagul Fibrinolysis 2014; 25(05):444-450 